\title{
A LONGA VIDA DO CÓDIGO CIVIL ${ }^{1}$
}

THE CIVIL CODE'S LONG LIFE

José Reinaldo de Lima Lopes*

\begin{abstract}
Resumo:
O texto coloca em dúvida a ideia de que o Código Civil esteve vigente por longo tempo no Brasil. Ao contrário, o artigo argumenta que o Código foi sendo alterado e o que permaneceu em vigor foi uma certa ideologia do Direito Civil, fundada sobretudo em mitos de continuidade. Essa ideologia dificultou a renovação do pensamento jurídico brasileiro porque o ensino se dava sobre as bases da ideia unitária do código e não sobre a realidade do direito positivo ou das práticas cotidianas dos cidadãos e dos juristas.
\end{abstract}

Palavras-chave: Teoria do direito. Eficácia do Código Civil. Mito da continuidade. Mudança legal. Mudança social.

\begin{abstract}
:
The paper raises doubts about the idea that the Civil Code was in force for a long time in Brazil. Instead, it argues that the Code underwent changes and what remained in force was a given ideology of private law, founded mostly on myths of continuity. Such an ideology made the renewal of Brazilian legal thought difficult, as legal teaching was conducted on the basis of a unitary idea of the Code, not on the reality of positive law or the daily practices of citizens and lawyers.
\end{abstract}

Keywords: Legal theory. Effectiveness of the Civil Code. Myth of continuity. Legal change. Social change.

Quando comparamos código comercial, código civil e constituição no Brasil fica evidente a longevidade do primeiro, com relação aos dois outros, e a incomparável longevidade do segundo com as constituições. O Código Comercial, editado em 1850, foi sobrevivendo em sua parte geral e chegou até 2002. Matérias de falências e de sociedades sofreram seguidas mudanças seja durante o Império, seja depois de proclamada a República. A disciplina das anônimas e das sociedades mercantis foi muito afetada no último quartel do século XIX, e a partir de 1919 - da lei sobre sociedade por quotas de responsabilidade limitada - a prática societária mudou enormemente. O mesmo se diga a respeito da disciplina dos títulos de crédito, muito limitada em 1850, e cheia de novidades

\footnotetext{
Agradeço aos mestrandos Ariel Engel Peso, Gabriel Andrade Salles Brasil Maia Siqueira, Rafael Parisi Abdouch e Vinícius Astolpho Vieira a ajuda na organização do evento em que este texto foi apresentado.

* Professor Titular do Departamento de Filosofia e Teoria Geral do Direito da Faculdade de Direito da Universidade de São Paulo.
} 
no início do século XX, novidades contempladas em legislação extravagante. Mesmo assim, falava-se de certa continuidade.

Desde a sanção do Código Civil em janeiro de 1916, vivemos sob seis diferentes constituições, se nesse número incluirmos as duas constituições ditatoriais de 1937 e 1967 (1891, 1934, 1937*, 1946, 1967*, 1988). O fenômeno não é exclusivamente brasileiro. Bem ao contrário, repete-se em diversos países, a começar da própria França, onde o Código Civil atravessou idas e vindas entre monarquia e república, revoluções, golpes, profundas alterações sociais. E o que dizer da Alemanha, cujo BGB continuou vigente em meio ao regime de total exceção que foi o nazismo? ${ }^{2} \mathrm{O}$ caminho da Itália foi diferente, e o Código de 1942 parece muito mais influenciado pelo clima da época do que outros. No Brasil, em período paralelo - a ditadura do Estado Novo de 19371945 - pretendeu-se também introduzir mudanças significativas em nossa lei civil sem grande sucesso. Logrou-se alterar a Lei de Introdução ao Código Civil, hoje chamada Lei de Introdução às Normas do Direito brasileiro, e, com isso, incentivar interpretação mais funcionalista em nossa doutrina. ${ }^{3}$ Os militares da ditadura de 1964 empenharam-se também na tarefa de alterar o Código Civil e tiveram mais sucesso - e paciência - do que Vargas no longo prazo, pois afinal foi durante seu regime e sob a condução de um seu apoiador, Miguel Reale, que surgiu o embrião do Código de 2002.

Parece, pois, que constituições dependem mais das contingências da política, e no Brasil seguem o tempo rápido do jornalismo, enquanto os códigos estão abrigados na permanência, seja ela ciência, seja da vida cotidiana, a despeito de Teixeira de Freitas haver notado na Consolidação das leis civis que

uma legislação civil é sempre dominada pela organização política. Uma legislação moldada para uma monarquia absoluta, sob o predomínio de outras idéias, deve muitos

2 No caso da Alemanha a historiografia mais recente já se debruçou sobre essa questão em importantes obras, tais como WEGERICH, Christine. Die flucht in die grenzenlosigkeit: Justus Wilhelm Hedemann (1878-1963). Tübingen: Mohr Siebeck, 2004. RÜTHERS, Bernd. Die unbegrenzte auslegung: zum wandel der privatrechtsordnung im nationalsozialismus. Tübingen: Mohr Siebeck, 2005. JOERGES, Christian; GHALEIGH, Navraj Singh. Darker legacies of law in Europe. The shadow of national socialism and fascism over Europe and its legal traditions. Oxford/Portland: Hart Publishing, 2003. NÖRR, Knut Wolfgang. Zwischen den Mühlsteinen: eine privatrechtsgeschichte der Weimarer Republik. Tübingen: Mohr Siebeck, 1988. Para a Itália a bibliografia é também abundante e cita-se apenas a título exemplificativo BIROCCHI, Italo. Sul crinale del 1944: Filippo Vassalli e la reinvenzione del ruolo della Facoltà di Giurisprudenza della Sapienza di Roma dopo la caduta del fascismo. In: CAVINA, Marco (Org.). Giuristi al bivio: le facoltá di giurisprudenza tra regime fascista ed etá repubblicana. Bologna: Cooperativa Libraria Universitaria Editrice Bologna, 2014, ou o volume temático de Quaderni fiorentini per la storia del pensiero giuridico moderno, Milano, v. 28, tomo 1-2, 1999. Os franceses também têm suas histórias... Entre os espanhóis vejase RIVAYA GARCÍA, Benjamín. Filosofia del derecho y primer franquismo (1937-1945). Madrid: Centro de Estudios Políticos y Constitucionales, 1988.

3 Para a tentativa de Francisco Campos... 
casos repugnar às condições do sistema representativo. Quantas leis entre nós não incorreram desde logo em virtual e necessária revogação, por se tornarem incompatíveis com as bases da Carta Constitucional? (FREITAS, 19-?, p. xxxiii).

Gostaria de refletir brevemente sobre essa situação, sobre a permanência e a volatilidade da legislação no direito civil, sobre suas relações com a contingência do mundo social.

O código brasileiro foi precedido de décadas de discussão, no que também se assemelha a outras experiências codificatórias. No caso do Brasil essas décadas viram nossos codificadores discutirem pontos bem determinados. Em primeiro lugar, a grande novidade inaugurada por Teixeira de Freitas (1816-1883) dizia respeito à divisão ou estrutura mesma de um código. O "jurisconsulto do Império"4 considerava insuficiente e defeituosa a classificação usada pelo Código Civil dos franceses: ela revelava mais tradição do que ciência, mais conservadorismo do que reflexão racional. Mesmo inspirado largamente no direito natural racionalista e moderno, o código francês conservava as tradicionais distribuição das matérias em sua estrutura, adaptava-se à tripartição herdada das Instituicções: pessoas, coisas, obrigações (ações, nas Instituta de Gaio e Justiniano). Para Teixeira de Freitas a divisão estrutural da lei deveria espelhar a natureza das relações jurídicas e isso o código francês não fazia: dividido em três livros, sobre pessoas, bens e obrigações, parecia aproximar-se da proposta jusnaturalista de um Jean Domat, antes que da clareza dos conceitos iniciada pelos novos estudos alemães.

A controvérsia havia sido intensa e o próprio Teixeira de Freitas não estava totalmente seguro a respeito de como distribuir as matérias em seu código. Sabia que era da maior importância que isso fosse feito adequadamente, mas a matéria consumiu-o por muito tempo. Já na Introdução à Consolidação das leis civis dizia com clareza: "Dispor os elementos para a projetada reforma, tal é o pensamento que nos domina." (FREITAS, 19-?, p. xxxix). Na Consolidação ele organiza o direito vigente em dois grandes blocos. Uma parte geral, que trata das pessoas e das coisas, e uma parte especial, dividida em direitos pessoais (que se distribuem em direitos nas relações de família e direitos nas relações civis) e direitos reais, entre os quais inclui os direitos de herança e as questões de prescrição aquisitiva (usucapião). No Esboço, essa distribuição é reelaborada e já se torna muito familiar. Uma Parte Geral (Livro I), onde se acham três seções: das pessoas, das coisas e dos fatos. Uma Parte Especial o Livro II, em que se encontram os direitos pessoais, dos quais aparece (a) uma disciplina abstrata seguida de seções sobre (b) as

Conforme o sugestivo título da biografia escrita por MEIRA, Silvio. Teixeira de Freitas: o jurisconsulto do Império: vida e obra. Rio de Janeiro: José Olympio/Instituto Nacional do Livro, 1979. 
relações de família e (c) as relações civis. Segue-se, na mesma parte especial, o Livro III, dos direitos reais, dividido em (a) direitos reais em geral, (b) direitos sobre coisas próprias, e (c) direito sobre coisas alheias. O trabalho não foi completado, e faltaram as disposições sobre sucessões (heranças), concurso de credores e prescrição aquisitiva, como ele antecipara na Consolidação.

Tanto Coelho Rodrigues (1846-1912) quanto Clóvis Bevilaqua (1859-1944) confessaram não apenas a inspiração no trabalho de Freitas quanto a importância desse esforço de classificar, organizar, abstrair. Escrito entre 1891 e 1893, o projeto de Coelho Rodrigues adotou já a divisão que viria a ser incorporada no projeto Clóvis Bevilaqua e, finalmente, no Código Civil de 1916. De Teixeira de Freitas, o professor de Recife acatou a ideia de uma parte geral, na qual se tratava dos elementos de todos os direitos, das pessoas e dos bens, além das relações possíveis entre as pessoas e seus direitos, oriundas de fatos ou negócios, de negócios e relações jurídicas, e assim por diante. A divisão geral do projeto de Coelho Rodrigues também era semelhante à proposta de Freitas, pois agrupava os direitos pessoais em um grande livro, o das Obrigações, e os direitos sobre coisas em outro, o dos Direitos Reais. As outras matérias foram distribuídas entre um livro de família e outro de sucessões.

Qualquer um de nós que leia esses trabalhos vê-se logo atraído pela discussão abstrata e pelos critérios de racionalização das relações chamadas civis, ou seja, do nosso cotidiano. Essa força atrativa das grandes classificações é o que nos interessa no direito civil. É a ela que atribuímos o caráter científico de nossas atuais reflexões. Vamos então examinar mais de perto como, por meio dela, predicamos a longa vida do código civil.

Quando se discute a atualização do ensino jurídico e mesmo a atualização do direito, diante das mudanças sociais, sempre existem os que alegam o atraso da legislação. A sobrevivência de legislação antiquada regendo situações sociais novas parece sempre um bom suspeito para nossas críticas. Gostaria de colocar essa ideia em xeque.

Vejamos o caso do Código Civil brasileiro. Seu projeto foi elaborado em 1899 e enviado ao Congresso Nacional em 1900. Durante dezesseis anos tramitou no Parlamento e durante esse período o Brasil mudava. Em lugares como Rio de Janeiro e São Paulo nasciam indústrias e atividades que logo fizeram aparecer um embrião de classe operária. E enquanto tramitava o projeto, foi aprovada a Lei n. 2.681, em 7 de dezembro de 1912, pela qual se introduzia a responsabilidade objetiva das companhias de estrada de ferro pelos acidentes resultado de suas atividades. Em 1917, ano de entrada em vigor do Código, aconteceu a histórica greve geral em São Paulo. O código entrava em vigor, mas a ordem legal que ele veiculava não se detinha.

No campo das obrigações, apareceu já em 1919 a lei de sociedades por responsabilidade limitada (Decreto n. 3.708, de 10 de janeiro de 1919). O tema já havia 
sido ventilado cinquenta anos antes, num projeto apreciado pelo Conselho de Estado, e fora introduzido no projeto de Código Comercial do jurista e professor Inglês de Sousa (1853-1918), mas tornou-se lei apenas em 1919 (projeto do deputado gaúcho Joaquim Luis Osório), quando já vigorava o Código Civil. Este modelo de sociedade tornou-se o mais usado no Brasil, tanto para sociedades civis quanto para sociedades comerciais. Foram parar no esquecimento muitas das formas sociais previstas no Código Civil e no Código Comercial.

Em 1934, dezessete anos depois do Código, entrou em vigor a Lei de Luvas, ou lei de locação comercial (Decreto n. 24.150, de 20 de abril de 1934), criando aquilo que os juristas começaram a chamar de propriedade comercial. Lá se foi outro pedaço do Código Civil, com ou quase desmembramento da propriedade entre um rendeiro, o proprietário (locador), e um capitalista, o comerciante ou industrial (locatário). Sendo aparentemente uma lei processual, pois dizia respeito à ação para renovação compulsória da locação, a lei alterou o regime da locação e de uso da propriedade imóvel propriamente dita. Com a jurisprudência e a doutrina em torno dela (a "teoria do estabelecimento", do "fundo de comércio"), chegou a instituir, na prática, uma espécie de direito sobre a propriedade. Em 10 de dezembro de 1937, o Decreto-Lei n. 58 alterou também o sistema de transmissão de propriedade fundiária, ao determinar que os compromissos de venda e compra de lotes de terra poderiam ser diretamente inscritos como título de propriedade, dispensada a escritura pública. Também neste caso a lei parece tratar apenas de aspectos acessórios, ou mesmo de matéria processual, pois objetivava a adjudicação compulsóriajudicial, portanto - do bem prometido à venda. Mas de fato criou nova forma de aquisição da propriedade imóvel. A Lei n. 5.049 de 1966 permitiu a compra e venda de imóveis e a constituição de hipoteca por instrumento particular, no âmbito do Sistema Financeiro da Habitação, criado pelo regime militar para incentivar a construção civil brasileira. O regime de hipotecas para a maioria das pessoas físicas e para boa parte da chamada indústria da construção civil (incorporadoras e construtoras de imóveis residenciais urbanos) passou a ser em grande parte o regime do Sistema Financeiro da Habitação. Para a hipoteca em financiamentos industriais o sistema também foi alterado na década de 1960 seja pelo novo ordenamento do crédito industrial (Decreto-Lei n. 412, de 1969), seja pela criação da cédula rural hipotecaria (Decreto-Lei n. 167, de 1967).

Aparentemente todo o regime de propriedade estaria no Código Civil, mas já vimos que em 1934 estabeleceu-se uma nova espécie de propriedade, a propriedade comercial. E as constituições brasileiras, a partir de 1934, indicavam já uma divisão do regime de propriedade, ao discipliná-la, de um lado como garantia individual e pessoal, e de outro como parte da organização econômica (const. 1934, art. 113, 17 x art. 115, caput, que fala de liberdade econômica). 
No direito de família as mudanças foram mais lentas. Clóvis insistia que seu projeto tornava a sociedade conjugal mais igualitária, embora conservasse a ideia de que muitos direitos pretendidos pelas mulheres levariam a uma ginecocracia indesejável (BEVILAQUA, 1900, p. xl, 1906, p. 94-95).5 A despeito de sua intenção igualitária, seu projeto conservou a ideia de que as mulheres casadas sofriam limites a sua capacidade, em nome da sociedade conjugal (art. $6^{\circ}$ do Projeto). Lembremos que as mulheres não votavam, o que só vieram a fazer no Brasil em 1934, e conforme a classe social a que pertencessem não exerciam certas profissões. A primeira grande mudança no regime da família veio em 1962, com a Lei n. 4.121 de 27 de agosto de 1962, o chamado estatuto da mulher casada, que aboliu a subordinação da mulher ao marido em diversos casos e eliminou o inciso II do art. $6^{\circ}$ do Código Civil, pelo qual a mulher casada se considerava relativamente incapaz. O passo seguinte foi a aprovação do divórcio. Clóvis não o adotada justificando que a monogamia era a tendência natural da espécie humana, uma aquisição evolutiva. Em 1934 a indissolubilidade do matrimônio foi alçada ao estatuto de disposição constitucional (art. 144), repetido em 1937 (art. 123), 1946 (art. 163) e 1967 (art. 167, § $1^{\circ}$ ) e só com a Emenda Constitucional n. 9, de 1977, a dissolução do vínculo foi permitida.

Não precisamos falar do direito do trabalho, que se tornou autônomo a partir dos anos 1930, nem do direito de propriedade industrial, que desde 1971 constituiuse com regulamentação autônoma (Lei n. 5.772.71, chamada de Código da Propriedade Industrial), nem do direito de seguros, cujas operações foram consolidadas e organizadas pelo Decreto-Lei n. 73 de 1966 e já vinham sofrendo alterações desde, pelo menos, 1930 (quando da criação do Instituto de Resseguros do Brasil), prosseguindo com a ampliação dos seguros obrigatórios em toda parte.

Em outras palavras, quando olhamos para o campo do direito privado em geral e do direito civil em particular, vemos mudanças em toda parte. O Código Civil, portanto, foi deixando de ser a única lei vigente no país para as matérias que ele mesmo regulara inicialmente. Um civilista consciente dessas transformações já levantava o assunto entre nós muitos anos atrás. Tratando dos direitos reais dizia ele que nosso Código Civil

já sexagenário e mutilado não enquadra mais todo o direito brasileiro das coisas. Está cercado de leis extravagantes, que não se limitam à limpeza do terreno para melhor trânsito de institutos trôpegos e caducos, mas vão muito mais adiante na medida em que ganham nova significação e atribuem

Cf. BEVILAQUA, Clóvis. Projecto de codigo civil brazileiro. Rio de Janeiro: Imprensa Nacional, 1900. p. xl, e BEVILAQUA, Clóvis. Em defeza do projecto do codigo civil brazileiro. Rio de Janeiro: Livraria Francisco Alves, 1906. p. 94-95. 
nova função ao direito nuclear e de propriedade. (GOMES, 1981, p. 30).

Como poderíamos falar da longa vida do código civil diante de tantas e muitas vezes tão profundas mudanças?

Creio que sua longa vida deve-se não a sua vigência e validade formais. O Código Civil de 1916, quando foi substituído pela Lei n. 10.406 de 2002 - o novo Código Civil -, vigia em certos campos apenas fragmentadamente. Tinha, no entanto a força que lhe era emprestada da doutrina jurídica. Ele deixava sua marca nas faculdades de direito e nos manuais por meio dos quais os alunos entravam nesse campo. Os manuais, e os próprios currículos das faculdades de direito conservavam do Código Civil a mesma divisão de livros e de matérias. E permitiam que se ensinasse direito civil pelo código, deixando a legislação extravagante como nota de rodapé ou como exceção ou, ainda, como alteração recente. Os alunos eram, portanto, obrigados a aprender direito civil por meio de um ideário ou ideal, ao qual a realidade legislativa do país já não correspondia. $\mathrm{O}$ que dizer da realidade social?

Para os historiadores é evidente que a vigência de um Código, como das leis em geral, não consiste apenas na totalidade de seus comandos, pois os comandos nunca se aplicam sem um articulado conceitual que lhes dá inteligibilidade geral. Assim, no campo do direito civil, como em qualquer outro campo do direito, é a doutrina que fornece os critérios para a leitura, compreensão e aplicação da lei. E a doutrina civilista não escapou aos embates e às mudanças. Temos então dois elementos importantes para conjugar: as leis extravagantes que foram a pouco e pouco incorporando situações novas (como as do inquilinato), ou criando instrumentos novos (como os direitos de garantia e títulos hipotecários), de um lado, e a doutrina jurídica, que articulava num todo inteligível o campo do direito civil ou privado. E durante um bom período essa doutrina esteve dividida - e talvez ainda esteja - em dois ramos diferentes. De um lado, a doutrina dos manuais, mais comportada, mais exegética, mais apegada ao texto do Código e para a qual a legislação extravagante vai se parecendo mais com as exceções do que com os casos frequentes. De outro lado uma doutrina mais inquieta, mais reflexiva e mais conceitual, que aparecia nos debates nas revistas jurídicas, nos ensaios monográficos, nas teses acadêmicas. Embora de grande impacto, talvez não circulassem pelas salas de aula, senão em versões muito simplificadas e reverenciais. Penso aqui, por exemplo, no surgimento de uma doutrina da responsabilidade civil que procurou dar conta mais organicamente do fenômeno da massificação, da industrialização e, por isso, da responsabilidade limitada. Penso também no caso dos contratos de adesão. Apenas dois exemplos, dos muitos que poderíamos citar: significativos, porém, das relações entre doutrina e lei. Mas o que parece ter acontecido foi que na esfera da transmissão do conhecimento jurídico, devido a fatores que não se pode aqui explicar em detalhe, os alunos, que viriam a serem os operadores 
do direito assim que saíssem da faculdade, adquiriam uma visão panorâmica propiciada pelos manuais e pelos cursos, e não tanto uma visão dos crescentes problemas e conflitos da sociedade em transformação.

Um bom exemplo dessa forma de ensinar encontrava-se num dos mais divulgados manuais de direito civil, do meu saudoso e nobre professor Washington de Barros Monteiro. Ao introduzir o tema da propriedade em seu curso, dizia ele que "a exata concepção é a de que a propriedade é inerente à própria natureza humana, ela representa a condição de existência e de liberdade de todo o homem." (MONTEIRO, 1974, p. 87). Não apareciam aí nem a condição que Locke mesmo impusera à propriedade (e a diferença entre propriedade natural e propriedade civil), nem as ressalvas feitas por Pontes de Miranda a respeito da extensão do instituto, desde seus comentários à Constituição de 1937. Para Locke, a propriedade natural, aquela que manifesta a liberdade da pessoa humana, está limitada pela escassez de recursos e ao longo da história pela introdução do dinheiro. Se não houver abundância de terras da mesma qualidade, dizia ele, seria preciso disciplinar a apropriação das terras boas. O dinheiro, e a sociedade civil, por seu turno fazem desaparecer a propriedade natural e instituem a propriedade civil. (LOCKE, 2005, p. 412-417). Pontes de Miranda chamou a atenção para as mudanças havidas no direito, dizendo que os juristas ainda não se haviam habituado ao fato de que a definição de propriedade, ou melhor, o conceito de propriedade, não se encontrava mais consultandose o Código Civil apenas, senão examinando seu fundamento constitucional. ${ }^{6}$

Esse descompasso entre as mudanças na sociedade, e a permanência do espírito e da doutrina do código, quando o mesmo código já havia mudado, ampliou-se com o passar do tempo. Como dito antes, embora a doutrina se agitasse em certas esferas, ela não se disseminava no ensino, o que provocou a permanência de uma leitura tímida do sistema brasileiro.

Hoje, a maior parte da vida contratual existe fora dos modos previstos esquematicamente no Código Civil. Digo esquematicamente porque nele se encontram, como deve ser em boa técnica codificadora, apenas os essentialia negotii. Nossa vida se realiza por meio de relações de consumo, e a vida das unidades de produção por meio de contratos em cadeia, ou de contratos com o Estado, em diversas formas de concessão ou de negócios altamente regulados. Onde aparece isso em nossos manuais de direito civil mais tradicionais? Nos casos excepcionais, nas notas de rodapé? Como esses casos são apresentados aos alunos, os que mais tarde vão aplicar o direito?

6 Cf. MIRANDA, Franciso Cavalcanti Pontes de. Comentários à constituição da república dos Estados Unidos do Brasil. Rio de Janeiro: Editora Guanabara, 1937. v. 2. p. 182-185. MIRANDA, Franciso Cavalcanti Pontes de. Os fundamentos atuaes do direito constitucional. Rio de Janeiro: Empresa de Publicações Thecnicas, 1932. p. 380-382. 
E as formas de propriedade? O que dizer delas? Já nas primeiras décadas do século XX alguns autores insistiam no desaparecimento da propriedade imaginada nos códigos civis. Dois exemplos apenas bastariam para isso: na Europa Karl Renner, e seu Instituições de direito privado e sua função social, e nos Estados Unidos John Commons e seu Legal foundations of capitalism. Como o direito civil ensinado nas escolas foi capaz de incorporar isso? Como foi capaz de dialogar com o debate a respeito dos bens comuns, desencadeado na segunda metade do século XX seja nas teorias da escolha racional, dos jogos ou da famosa tragédia dos bens comuns?

O direito civil, de tão fundamental importância na cultura jurídica ocidental, distanciou-se daquilo que ordinariamente acontece. Melhor, o ensino do direito civil distanciou-se do que ordinariamente acontece: deixamos de olhar para o que acontece o mais das vezes, como, por exemplo, os contratos de consumo, para olhar em primeiro lugar para o texto do código. Disso resultou que a doutrina do direito civil ficou mais presa àquilo que foi consagrado como doutrina num certo período, do que ao exame do que acontece. Em vez de usar a lente da doutrina para ler as práticas nascentes, a doutrina passou a examinar sobretudo o código. Desta perspectiva, a doutrina tomou o código como regra, e todas as adaptações do direito civil ao mundo contemporâneo como exceções. Esqueceu-se daquilo que Pompônio havia dito: "Convém instituir os direitos a partir daquilo que normalmente acontece" (D. I, III, 3).

E o que dizer das inúmeras questões relativas à personalidade, ao sujeito de direito, ao pluralismo de situações, ao desenvolvimento recente dos direitos de identidade, do direito das culturas, dos conflitos de regras entre etnias? Essas eram matérias essenciais ao pensamento e à teoria geral do direito civil. Parece que os civilistas relegaram estas coisas à política quando muito, aferrando-se aos esquemas do início do século XX. Mas seria tarefa do pensamento jurídico propriamente revisitar esses conceitos diante das inumeráveis exigências sociais de mudança. Em poucas palavras, vinha chegando o momento de oferecer uma nova introdução geral ao direito civil, ou seja, uma concepção que pudesse dar conta de forma mais geral do sentido que poderia ter uma lei geral das relações privadas.

São apenas indicações do quanto a longa vida do Código Civil é uma narrativa mítica no Brasil, mas um mito que extrai alguma plausibilidade do fato de viver no imaginário de alguns juristas e sobretudo do fato de viver nos manuais e no ensino tradicional do direito. O que sobrevive do código é uma espécie de antropologia

D. I, III, 3 “(Pompônio, lib. 25, ad Sabinum) Jura constitui oportet, ut dixit Theophrastus, in his quae epi to pleiston, id est, ut plurimum, accidunt, non quae ek paralogou, ide est, ex inopinato." Celso afirmava coisa semelhante, conforme se conservou nos fragmentos seguintes: "D. I, III, 4 (CELSO, lib. 5 Digestorum) Ex his quae forte uno aliquo casu accidere possunt, jura non constituuntur. D. I, III, 5 (id.) Nam ad ea potius debet aptari jus, quae et frequenter, et facile, quam aut per raro eveniunt". 
jurídica, antropologia no sentido filosófico do termo, perpetuada pela nossa maneira de ensinar o direito. Foi uma visão do mundo social. Temo dizer que foi um abandono de uma importante e sofisticada reflexão jurídica que talvez pudesse contribuir, em meio a muitos outros saberes, para a vida propriamente. Como foi discutido no colóquio em mais de uma das intervenções, método e conteúdo, sintaxe e semântica, ciência e ideologia, alimentam-se reciprocamente. Ressaltando o que já foi dito, os historiadores do direito têm responsabilidades como juristas e como formadores de juristas.

Esta reunião de estudiosos da história em torno de uma data, a do centenário da codificação civil brasileira, cujos textos se publicam a seguir, foi uma reunião de historiadores, não de antiquários, da qual devemos retirar ideias, sugestões, críticas úteis para o futuro de nossas vidas sociais.

São Paulo, agosto de 2016.

\section{Referências}

AA. VV. Quaderni fiorentini per la storia del pensiero giuridico moderno, Milano, v. 28, tomo 1-2, 1999.

ALVES, José Carlos Moreira. Panorama do direito civil brasileiro: das origens aos dias atuais. Revista da Faculdade de Direito da Universidade de São Paulo, São Paulo, v. 88, p. 185-238, jan./ dez. 1993.

BEVILAQUA, Clóvis. Em defeza do projecto do codigo civil brazileiro. Rio de Janeiro: Livraria Francisco Alves, 1906.

. Projecto de codigo civil brazileiro. Rio de Janeiro: Imprensa Nacional, 1900.

BIROCCHI, Italo. Sul crinale del 1944: Filippo Vassalli e la reinvenzione del ruolo della Facoltà di Giurisprudenza della Sapienza di Roma dopo la caduta del fascismo. In: CAVINA, Marco (Org.). Giuristi al bivio: le facoltá di giurisprudenza tra regime fascista ed etá repubblicana. Bologna: Cooperativa Libraria Universitaria Editrice Bologna, 2014.

FREITAS, Augusto Teixeira de. Consolidação das leis civis. Rio de Janeiro / Paris: Livraria Garnier, 19-?.

GOMES, Orlando. Direitos reais no Brasil e em Portugal. In: GOMES, Orlando. Escritos menores. São Paulo: Saraiva, 1981.

JOERGES, Christian; GHALEIGH, Navraj Singh. Darker legacies of law in Europe. The shadow of national socialism and fascism over Europe and its legal traditions. Oxford/Portland: Hart Publishing, 2003. 
LOCKE, John. Dois tratados sobre o governo. 2. ed. Tradução Julio Fischer. São Paulo: Martins Fontes, 2005.

MEIRA, Silvio. Teixeira de Freitas: o jurisconsulto do Império: vida e obra. Rio de Janeiro: José Olympio/Instituto Nacional do Livro, 1979.

MIRANDA, Franciso Cavalcanti Pontes de. Comentários à constituição da república dos Estados Unidos do Brasil. Rio de Janeiro: Editora Guanabara, 1937. v. 2.

. Os fundamentos atuaes do direito constitucional. Rio de Janeiro: Empresa de Publicações Thecnicas, 1932.

MONTEIRO, Washington de Barros. Curso de direito civil. Direito das coisas. 13. ed. São Paulo: Saraiva, 1974. v. 3.

NÖRR, Knut Wolfgang. Zwischen den Mühlsteinen: eine privatrechtsgeschichte der Weimarer Republik. Tübingen: Mohr Siebeck, 1988.

RIVAYA GARCÍA, Benjamín. Filosofia del derecho y primer franquismo (1937-1945). Madrid: Centro de Estudios Políticos y Constitucionales, 1988.

RÜTHERS, Bernd. Die unbegrenzte auslegung: zum wandel der privatrechtsordnung im nationalsozialismus. Tübingen: Mohr Siebeck, 2005.

WEGERICH, Christine. Die flucht in die grenzenlosigkeit: Justus Wilhelm Hedemann (1878-1963). Tübingen: Mohr Siebeck, 2004. 
